\title{
Chapter 3 \\ The Four Values Framework: Fairness, Respect, Care and Honesty
}

\begin{abstract}
Values inspire, motivate and engage people to discharge obligations or duties. This chapter defends the values approach in the context of guarding against ethics dumping, the practice of exporting unethical research from higher-income to lower-income settings. A number of essential questions will be answered: What are values? What is the meaning of the word "value"? Why does it make sense to choose values as an instrument to guide ethical action in preference to other possibilities? And what is meant by fairness, respect, care and honesty? It is concluded that values can provide excellent guidance and aspiration in the fight against ethics dumping, and are therefore a well-chosen structure for the Global Code of Conduct for Research in Resource-Poor Settings.
\end{abstract}

Keywords Values $\cdot$ Virtues $\cdot$ Fairness $\cdot$ Respect $\cdot$ Care $\cdot$ Honesty

\section{Introduction}

Many celebrated documents which advocate for a better world include a preamble that mentions values. For instance, at the international level, the Universal Declaration of Human Rights (UN 1948) lists four values in the first sentence: dignity, freedom, justice and peace in the world. The first sentence of the Convention on Biological Diversity (UN 1992) refers to "the intrinsic value of biological diversity and of the ecological, genetic, social, economic, scientific, educational, cultural, recreational and aesthetic values of biological diversity" (emphasis added).

Other national or professional codes have incorporated values prominently into individual articles. For instance, at the national level in the UK, the first item of The Code: Professional Standards of Practice and Behaviour for Nurses, Midwives and Nursing Associates, reads: "Treat people with kindness, respect and compassion" (NMC 2018).

In some codes one has to search to find obvious references to values as they are often incorporated in a more implicit manner, such as in the Declaration of Helsinki 
(WMA 2013), which speaks of "safety, effectiveness, efficiency, accessibility and quality" in article 6 .

When developing the Global Code of Conduct for Research in Resource-Poor Settings (GCC), a unique approach emerged naturally from the process employed. Its underpinning values materialized ahead of its final articles through an investigation into the risks of exploitation in international collaborative research (Chapter 5), and from a global engagement and fact-finding mission (Chapter 6).

It soon became clear that fairness, respect, care and honesty are all lacking, or deficient, whenever ethics dumping ${ }^{1}$ occurs, and that a loss of trust in researchers and research itself can result. What also emerged is that these values are shared across the range of cultures that were represented in the TRUST ${ }^{2}$ consortium. It was therefore possible to surmise that these shared values are vital for equitable research partnerships and to prevent ethics dumping. In other words, these values are necessary to foster an ethical culture in research, and are therefore values to which all researchers should aspire.

This chapter will answer some essential questions: What are values? What is the meaning of the word "value"? Why does it make sense to choose values as an instrument to guide ethical action in preference to other possibilities? And finally, what is meant by "fairness", "respect", "care" and "honesty"?

\section{The Meaning of "Value"}

Values pervade human experience (Ogletree 2004), and references to "values" are ubiquitous. With vast numbers of articles, books and internet sites offering advice on matters such as values we should live by, discovering our own values, changing our core values and achieving success through values, it is obvious that values are important to people.

The term "value" can be used in many different ways. ${ }^{3}$ With reference to the way in which people use the term, three primary meanings of "value" can be distinguished (see Fig. 3.1).

First, value can refer to measurability. Mathematics operates with values, which can, for example, be discrete or continuous. Artists might speak of colours having values, meaning the relative lightness or darkness of a colour. In music, a note value determines the duration of a musical note. Economists or art dealers might measure value in monetary terms; a particular company or a particular painting might be

\footnotetext{
${ }^{1}$ The export of unethical research from a high-income setting to a resource-poor setting with weaker compliance structures or legal governance mechanisms.

${ }^{2}$ TRUST was an EU-funded project which operated from 2015 to 2018 and developed the GCC, among other outputs. http://trust-project.eu/

${ }^{3}$ This section draws on unpublished work by Professor Michael Davis, a philosopher specializing in professional ethics.
} 
Fig. 3.1 The meaning of value

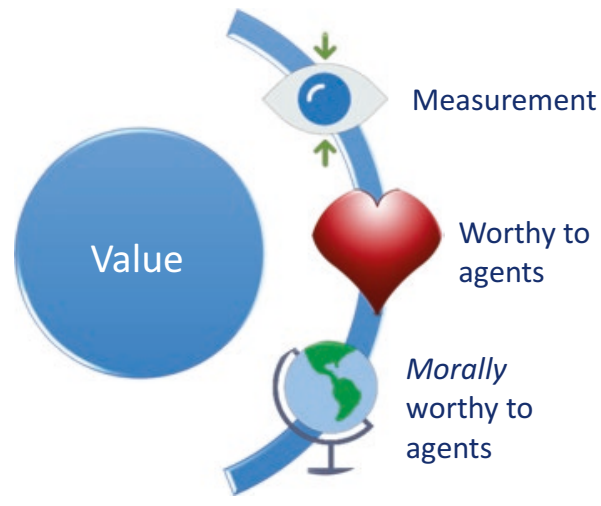

valued at a certain amount of money. Value, in this sense of the word, has no relationship to values such as admiration, approval or motivation.

Secondly, people can value certain features or entities. For instance, somebody might value money, fame or glory. For value to exist, there must be an agent (a person) who is doing the valuing, and the feature or entity must be worth something to this agent (Klein 2017). The values of one individual can be very different from those of another person. For instance, a regular income is worth a lot to a person who values routine and security; it can contribute to their wellbeing and happiness. Others, who value personal freedom more than routine and security, might be just as happy with occasional income, as long as they are not bound to a nine-to-five job. If most humans around the world value a particular thing, it can be described as a universal value.

Thirdly, values can refer to goals and ambitions, with a moral connotation. In business literature, for example, one often finds reference to value-led management or organizational values, and many institutions make a point of establishing, promoting and broadcasting their values. For instance, the stated values of the University of Central Lancashire (UCLan), at which several of the authors of this book are based, are: common sense, compassion, teamwork, attention to detail and trust (UCLan nd). These values are all morally positive and they are intended to guide the actions of students, staff and the institution itself. In this third sense of the word, moral values "will enable us to determine what is morally right or what is valuable in particular circumstances" (Raz 2001: 208). If most humans around the world share a particular moral value, it can be described as a universal moral value.

There are numerous advantages to having credible moral values at the level of organizations. Such values influence the culture of an organization (Martins and Coetzee 2011), which in turn has a positive impact upon corporate performance (Ofori and Sokro 2010), and job stress and satisfaction (Mansor and Tayib 2010), as well as business performance and competitive advantage (Crabb 2011). Furthermore, when employees' values are aligned with organizational values, this benefits both the wellbeing of individuals and the success of the organization (Posner 2010).

There are many internet sites that offer lists of core values. One of them (Threads Culture nd) includes 500 values, from "above and beyond" to "work life balance". 
Not all of these are moral values. For instance, this particular list includes values such as clean, exuberant, hygienic, neat, poised and winning (Threads Culture nd). Another site lists 50 values, including authenticity, loyalty and wisdom, and advises that fewer than five should be selected for leadership purposes (Clear nd).

The GCC is structured around four moral values: fairness, respect, care and honesty. These four values were not chosen from any existing lists; they emerged through in-depth consultation efforts around the globe (chapter 6). But why did the TRUST team choose moral values rather than other action-guiding moral modes for the GCC?

\section{What Can Guide Moral Action?}

The GCC is based on moral values, but the code authors could have opted to frame the code and guide action in other ways, including the following:

- Standards is a technical term used to achieve desired action. Standards are precise and give exact specifications, which are in many cases measurable, as in the maximum vehicle emissions allowed for cars. Standards can also be used in ethics. For instance, a well-known voluntary standard to guide ethical action is ISO 26000 (ISO not dated), developed by the International Organization for Standardization. ISO 26000 assesses the social responsibility of companies. Its guidance includes prohibitions against bribery, and the requirement to be accountable for any environmental damage caused.

- Principles are behavioural rules for concrete action. When you know the principle, you know what to do. For instance, in dubio pro reo has saved many innocent people from going to jail as it gives the courts very concrete advice. Literally translated, it means, "when in doubt, then for the accused" (a person remains innocent until proven guilty). This principle goes back to both Aristotle and Roman law.

- Virtues are beneficial character traits that human beings need to flourish (Foot 1978: 2f). One can observe them in real people or in fictional characters. England's semimythical Robin Hood, for instance, is seen as courageous and benevolent. He fights a David-and-Goliath battle against the Sheriff of Nottingham (courage) so that the poor have food (benevolence). Like values, for virtues to exist, there must be an agent (a person) who is being virtuous; virtues focus on the moral agent rather than on the standard or principle that underlies a decision.

- Ideals drive towards perfection and are highly aspirational. Some people will say "in an ideal world" to denote that something is unrealistic from the start. The ancient Greek philosopher Aristotle argued that we should strive towards perfection of character and that ideals can be guiding lights in character building. "Good character is an ideal outside of oneself that all strive for" (Mitchell 2015). 
So why were values chosen as the foundation for the GCC rather than standards, principles, virtues or ideals?

Ideals are the most aspirational of the concepts available to guide ethical action. However, hardly anybody can live up to all of their ideals. If one phrased an ethics code around ideals, those who should be led by the code might suggest that not reaching the ideals on every occasion would be acceptable. This is not the case. The 23 articles of the GCC (chapter 2) are not aspirational. They are mandatory.

Virtues are found both historically and internationally in many important documents of learning and wisdom. Famously, Aristotle (384-322 BC) linked human "happiness and wellbeing" to "leading an ethical life", guided by the cardinal values of courage, justice, modesty and wisdom (Aristotle 2004). According to Confucianism, the most important traditional virtues are said to be benevolence, righteousness, propriety, wisdom, trustworthiness, filial piety, loyalty and reciprocity (Wang et al. 2018). Virtues are a good way to drive ethical action, in particular global ethical action, but the TRUST team had good reason not to use virtues as the foundation of the GCC.

Virtues can be regarded as embodied ethical values because they are manifested in persons. One can learn a lot by observing real people (such as Mother Theresa or Nelson Mandela) and following their example. This makes virtue approaches very useful in leadership and mentoring (Resnik 2012). But not every researcher has access to mentors and learning via example. Besides, early career researchers are said to benefit more from rule-based approaches (Resnik 2012). Hence, while virtues were considered as a possibility for the foundation of the GCC, they were excluded because of their strong reliance upon the availability of role models.

Principles have a long-standing tradition in practical moral frameworks, especially principlism, the moral framework relating to bioethics developed by Beauchamp and Childress (2013). As argued in Chapter 4, we believe that the four principles of Beauchamp and Childress - autonomy, non-maleficence (do no harm), beneficence and justice - should instead be called values. Principles, as we understand them, are more concrete than values. Principles can provide almost immediate and very straightforward answers to ethical questions.

A famous principle in political philosophy is Rawls's difference principle. The principle holds that divergence from an egalitarian distribution of social goods (e.g. income, wealth, power) is only allowed when this non-egalitarian distribution favours the least advantaged in society (Rawls 1999: 65-70). In other words, if a particularly talented wealth creator increases the overall wealth pie so that the least advantaged in society are better off, she can receive a bigger share of the pie than others. Knowing about this principle gives answers to social philosophy questions, which the value of fairness or justice would not. Rawls applied the value of fairness to derive the more concrete difference principle. Principles are therefore too concrete and too prescriptive to form the foundation of the GCC. They would not leave enough room for local agreements between partners from high- and lower-income settings as envisaged by various GCC articles, such as article 1: "Local relevance of research ... should be determined in collaboration with local partners." 
Standards are even more specific than principles and have an even stronger action-guiding function. They prescribe very concrete activities in given settings. To formulate standards for ethical interaction between partners from different settings would certainly be too prescriptive. A standard cannot be diverged from (for example, a limit to vehicle emissions). For instance, if article $10^{4}$ were a standard, no exception to double ethics review would be possible. But there may be good reason to allow such an exception in certain circumstances. For instance, if ethics approval has been given in a high-income setting and community approval obtained in a host setting where no ethics committee operates, then it may be perfectly ethical to proceed.

The San community in South Africa, for instance, has no facility for providing ethics committee approval, but the South African San Council can provide community approval for research projects in the community (Chapter 7). A standard of double ethics review would forbid any research in the San community until an ethics committee were established, which might even undermine the San people's selfdetermined research governance structures. For this reason, it is clear that standards are too prescriptive to be applied to every setting, and might hinder valuable research.

This leaves ethical values, which operate as guides on the route to doing the right thing and are not overly prescriptive. They do not undermine the need to develop bespoke agreements across cultures via discussions between research teams and communities. At the same time, there is another, positive reason to choose values as the foundation for the GCC. Values inspire and motivate people to take action - and that is exactly what is needed to guard against ethics dumping.

\section{Values and Their Motivating Power}

Research stakeholders who are guided by values will hopefully be inspired and motivated by the GCC and not just follow its rules reluctantly or grudgingly. Why is that? Values can serve as motivating factors in promoting or inhibiting human action (Marcum 2008, Locke 1991, Ogletree 2004). The influence of personal values upon behaviour has become a subject of extensive research in the social sciences and in psychology, particularly over the past forty years, with just about every area of life being examined through the lens of personal values - for example, consumer practices (Pinto et al. 2011), political voting habits (Kaufmann 2016), employee creativity (Sousa and Coelho 2011), healthcare decisions (Huijer and Van Leeuwen 2000), investment decisions (Pasewark and Riley 2010), and sexuality and disability (Wolfe 1997), to name but a few.

\footnotetext{
${ }^{4}$ Local ethics review should be sought wherever possible. It is of vital importance that research projects are approved by a research ethics committee in the host country, wherever this exists, even if ethics approval has already been obtained in the high-income setting.
} 
Arguably the most prominent theory of the motivational power of human values was developed by social psychologist Shalom Schwartz, back in 1992. Schwartz's theory of basic values is distinctive because, unlike most other theories, it has been tested via extensive empirical investigation. Studies undertaken since the early 1990s have generated large data sets from 82 countries, including highly diverse geographic, cultural, religious, age and occupational groups (Schwartz 2012). Findings from Schwartz's global studies indicate that values are inextricably linked to affect. He claims that when values are activated, they become infused with feeling (Schwartz 2012). For example, people for whom routine and security are important values will become disturbed when their employment is threatened and may fall into despair if they actually lose their jobs. Correspondingly, when moral values like fairness or respect are important, people will react when they witness instances of unfairness or disrespect; they will feel motivated to respond in some way.

Schwartz's research investigated motivational values in general (combining our second and third meanings of "value"), and not just moral values. As noted earlier, people can be motivated by many different values, but interestingly, when asked to rank values in order of importance, the participants in Schwartz's studies consistently rated those with explicit moral connotations as the most important values (Schwartz 2012). This suggests that people hold their moral values in high esteem and can be strongly influenced by them.

\section{From Values to Action}

Ethical values give us direction but are not sufficient to make us ethical researchers who avoid ethics dumping. One can hold the value of honesty and yet fail to be an honest person. One can hold the value of respect and yet cause harm when disrespecting local customs. Values can motivate and they can help to establish moral goals, but they do not explain how to achieve them. A means of operationalizing values is needed.

One method would be to cultivate virtues that are aligned with the values. As noted above, virtues are positive character traits individuals build over time which are needed for human flourishing. Once a value such as honesty becomes second nature, one can say that honesty is a virtue of that person. If all researchers developed the virtues of fairness, respect, care and honesty, then being an ethical researcher would come naturally to them. However, this is far from easy, and the development of virtues takes time. It is perhaps possible for researchers who have worked in the field for many years, and have a wealth of knowledge and experience, but certainly not for young researchers who need training, guidance and practice.

Daniel Russell (2015: 37f) illustrates the challenge for virtue ethics in guiding specific action when he asks us to think about generosity:

Sometimes helping means giving a little, sometimes it means giving a lot; sometimes it means giving money, sometimes it means giving time, or just a sympathetic ear; sometimes it means offering advice, sometimes it means minding one's own business; and which of 
these it might mean in this case will depend on such different things as my relationship with my friend, what I am actually able to offer, why and how often my friend has problems of this kind, and so on.

For all those who are still developing their virtues, a code such as the GCC can help to guide action. As noted at the outset, people are much more contented and productive when their own values are aligned with company or institutional values and rules. It therefore made sense to align the articles of the GCC with those values that are necessary for ethical research and to which researchers must aspire. The values of fairness, respect, care and honesty provide the ethos, the motivation and the goals for ethical research. The 23 articles making up the GCC therefore enable operationalization of the values.

This leaves the task of outlining what is meant by each of the four values of fairness, respect, care and honesty, keeping in mind the following important points. First, precise specifications of values might be affected by customs and preferences, so that different cultures have different views on the exact content of the values. Second, the importance of process cannot be underestimated. The reason why articles $2^{5}$ and $4^{6}$ of the GCC emphasize inclusion is that the specification of what each value requires in a given setting needs to be determined collaboratively. As a result, this sketch of the content of the four values is brief and leaves room for regional variations.

\section{The Four Values}

\section{Fairness}

The terms "fairness", "justice" and "equity" are often used interchangeably. The TRUST consortium chose the term "fairness" in the belief that it would be the most widely understood globally. Philosophers commonly distinguish between four types of fairness (Pogge 2006) (see Fig. 3.2).

The most relevant fairness concepts in global research ethics are fairness in exchange and corrective fairness. In global collaborations, at least two parties are involved in a range of transactions. Typical fairness issues between partners from high-income countries (HICs) and those from low- and middle-income countries (LMICs) are:

- Is the research relevant to local research needs?

- Will benefit sharing take place?

- Are authors from LMICs involved in publications?

\footnotetext{
${ }^{5}$ Local communities and research participants should be included throughout the research process, wherever possible, from planning through to post-study feedback and evaluation, to ensure that their perspectives are fairly represented. This approach represents Good Participatory Practice.

${ }^{6}$ Local researchers should be included, wherever possible, throughout the research process, including in study design, study implementation, data ownership, intellectual property and authorship of publications.
} 


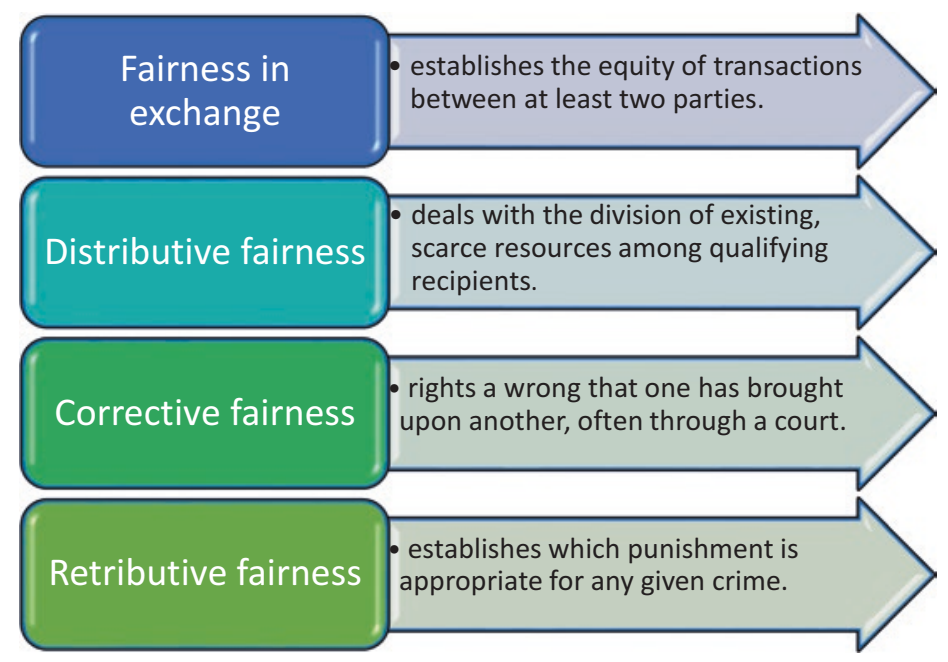

Fig. 3.2 Types of fairness

These are questions about fairness in exchange. For instance, LMIC research participants contribute to the progress of science, but this is only fair if the research is relevant to their own community or if other benefits are received where this is not possible. For instance, to carry the burden of a clinical study is only worthwhile for a community if the disease under investigation occurs locally and the end product will become available locally.

Corrective fairness, which presupposes the availability of legal instruments and access to mechanisms to right a wrong (e.g. a complaints procedure, a court, an ethics committee) is also important in global research collaborations. For instance, if no host country research ethics structure exists, corrective fairness is limited to the research ethics structure in the HIC, which may not have the capacity to make culturally sensitive decisions.

The broader question of what HICs owe LMICs falls under distributive fairness. One can illustrate the difference between fairness in exchange and distributive fairness using the example of post-study access to successfully tested drugs. In the first case (fairness in exchange) one could argue that research participants have contributed to the marketing of a particular drug and are therefore owed post-study access to it (should they need the drug to promote their health and wellbeing, and should they not otherwise have access to it). In the second case (distributive fairness) one could provide a range of arguments, for instance being a signatory to the Universal Declaration of Human Rights (UN 1948), to maintain that all human beings who need the drug should have access to it, and not just the research participants. These wider fairness issues cannot be resolved by researchers and are therefore not directly included in the GCC. Likewise, retributive fairness is less relevant as few ethics violations fall under the punitive and criminal law, and if they do, it is indeed criminal law that should be used to deal with a fairness violation. 


\section{Respect}

The term "respect" is used in many ethics frameworks. For instance, the Declaration of Helsinki (WMA 2013) notes in article 7:

Medical research is subject to ethical standards that promote and ensure respect for all human subjects and protect their health and rights. (emphasis added)

Its ubiquitous use does not, however, mean that "respect" is a clear term. In everyday life, it is used in the sense of deep admiration. For instance, somebody could say, "I respect the achievements of Nelson Mandela". However, that is not what is meant by respect in research ethics. The statement from the Declaration of Helsinki does not mean that research participants must be admired. To be respected in research ethics is almost the opposite. It means that one must accept a decision or a way of approaching a matter, even if one disagrees strongly. A case in point would be respecting the decision of a competent adult Jehovah's Witness to refuse a blood transfusion for reasons of religious belief, even if this means certain death.

Respect is therefore a difficult value, as there will be cases where one cannot accept another's decision. For instance, if a researcher learns about female genital mutilation being used as a "cure" for diarrhoea in female babies (Luc and Altare 2018), respecting this approach to health care is likely to be the wrong decision particularly as the practice is probably illegal. But the fact that respect may be difficult to operationalize in global research collaborations does not mean that it is a value one can dispense with.

There are many possible ways of showing respect that do not create conflicts of conscience. For instance, illiterate San community members should not be enrolled in research studies unless San leaders have been contacted first, in accordance with community systems. And researchers from HICs should not insist that LMIC ethics committees accept the format of the researchers' preferred ethics approval submission; instead the HIC researchers should submit the study for approval in the format required by the LMIC committee. This shows respect in international collaborative research.

While it may be difficult to imagine a situation where an HIC researcher is accused of being too fair, too honest or too caring, it is possible to be accused of being "too respectful" - for instance, if one tolerates major violations of human rights. It is indeed sometimes difficult to strike a balance between dogmatically imposing one's own approach and carelessly accepting human rights violations, but that is the balance researchers should strive for.

\section{Care}

Sometimes one word describes different concepts. This is the case with "care". The statement, "I care for my grandfather," can mean two diametrically opposed things. First, it could mean that the person is very attached to her grandfather even though she hardly ever sees him. Second, it could mean that she is the person who injects 
her grandfather with insulin, cooks his meals, and makes sure that his needs are taken care of every day, even if there is antipathy between them.

The meaning of the value of care in the context of global research ethics links more to the second use of the term; to look after or take care of somebody or something. As a main priority, one should take care of the interests of those enrolled in research studies to the extent that one always prioritizes their welfare over any other goals - for example, accepting the decisions of those who choose to withdraw from an ongoing study, even if this impairs the project's results. In line with article 8 of the Declaration of Helsinki (WMA 2013) that means:

While the primary purpose of medical research is to generate new knowledge, this goal can never take precedence over the rights and interests of individual research subjects.

This care applies across disciplines, not only in medical research, and it is not restricted to human research participants. Article 21 of the Declaration of Helsinki (WMA 2013) extends the care for research subjects' welfare to research animals. Likewise, care for environmental protection is increasingly included in research ethics processes and frameworks for responsible research. For instance, the European Commission's Horizon 2020 ethics review process addresses potentially negative impacts on the environment (Directorate General for Research 2019: section 7). Richard Owen et al. (2013) define responsible research and innovation as "a collective commitment of care for the future through responsive stewardship of science and innovation in the present", a statement that has clear relevance to environmental protection.

Researchers who take care to avoid negative impacts in their work will not "helicopter" in and out of a research area they are not familiar with, but will use systems of due diligence to ensure that risks are assessed and mitigated. For instance, an HIC research team that strips a local area of all doctors and nurses by attracting them into their high-tech research facility is not acting carefully and ethically.

Ideally, researchers who take good care will combine the two concepts mentioned above: they care about research participants, in the sense that the participants are important to them, and they feel responsible for the welfare and interests of those who contribute to their research, or might suffer as a result of it (including animals and the environment).

\section{Honesty}

Honesty is a value that does not need complicated explanations or definitions. In all cultures and nations, "Do not lie" is a basic prerequisite for ethical human interaction. It is so basic a value that its synonyms are often broad ethics terms. For instance, according to Google (2018), synonyms for "honesty" are:

moral correctness, uprightness, honourableness, honour, integrity, morals, morality, ethics, principle, (high) principles, nobility, righteousness, rectitude, right-mindedness, upstandingness 
What does need explaining, however, is the scope of the value of honesty in the context of global research ethics. Telling lies is only one possible wrongdoing in the context of a broad understanding of honesty. For instance, in research ethics it is equally unacceptable to leave out salient features from an informed consent process. While this might, strictly speaking, not involve a lie, concealing important information that might make a difference to someone's consent violates the value of honesty as much as lying. For this reason, research ethicists often use the terms "transparency" and "open communication" to ensure that all relevant information is provided so that research participants can make an informed choice about whether to participate or not.

In addition to lying and withholding information, there are other ways of being dishonest, in the sense of not communicating openly and transparently. For instance, in a vulnerable population with high levels of illiteracy, it can be predicted that a printed information sheet about research will not achieve informed consent. The same can be said for a conscious failure to overcome language barriers in a meaningful way: leaving highly technical English terms untranslated in information sheets can easily lead to misunderstandings.

Honesty is also related to research conduct other than interaction with research participants. Most prominently, the duties of honesty are described in research integrity frameworks: do not manipulate your data, do not put your name onto publications to which you have not contributed, do not waste research funds, to give only three examples. However, while the latter prescriptions for conduct with integrity in research are important, they are not directly linked to exploitation in global research collaboration and are not covered in the GCC. In this context, the European Code of Conduct for Research Integrity (ALLEA, 2017) is very helpful.

\section{Conclusion}

Standards, principles, values, virtues and ideals can guide moral action. At the foundation of the GCC are values. Why? For three main reasons:

1. Values inspire action; they motivate people to do things. For instance, when the value of fairness is threatened, people normally respond with action.

2. Values provide the golden middle way between being overly prescriptive and overly aspirational. Standards and principles require too much precision in their formulation and are too prescriptive in international collaborative research, while virtues and ideals are too aspirational in their demands of researchers.

3. Values emerged naturally from the major engagement activities undertaken prior to developing the GCC.

The eradication of ethics dumping requires not only moral guidance but also moral action to counter violations of fairness, respect, care and honesty. The 23 short, accessible articles of the GCC are intended to both guide and inspire researchers to act with fairness, respect, care and honesty. 


\section{References}

ALLEA (2017) The European code of conduct for research integrity. All European Academies, Berlin. https://www.allea.org/allea-publishes-revised-edition-european-code-conduct-research-integrity/

Aristotle (2004) Nicomachean Ethics (trans: Thomson JAK), 2nd edn. Tredennick H (ed). Penguin Classics, London

Beauchamp TL, Childress JF (2013) Principles of biomedical ethics, 7th edn. Oxford University Press, New York

Clear J (nd) Core values list. https://jamesclear.com/core-values

Crabb S (2011) The use of coaching principles to foster employee engagement. The Coaching Psychologist 7(1):27-34

Directorate General for Research (2019) Horizon 2020 Programme: guidance - how to complete your ethics self-assessment, version 6.1. European Commission. http://ec.europa.eu/research/ participants/data/ref/h2020/grants_manual/hi/ethics/h2020_hi_ethics-self-assess_en.pdf

Google (nd) Honesty: synonyms. https://www.google.com/search?q=honesty\&ie=\&oe=

Google (2018) Google search for "Honesty" conducted on 24 November 2018.

Huijer M, van Leeuwen E (2000) Personal values and cancer treatment refusal. Journal of Medical Ethics 26(5):358-362

ISO (nd) ISO 26000: social responsibility. International Organization for Standardization. https:// www.iso.org/iso-26000-social-responsibility.html

Kaufmann E (2016) It's NOT the economy, stupid: Brexit as a story of personal values. British Politics and Policy. London School of Economics and Political Science. http://blogs.lse.ac.uk/ politicsandpolicy/personal-values-brexit-vote/

Klein LA (2017) A free press is necessary for a strong democracy. ABA Journal. http://www.abajournal.com/magazine/article/free_press_linda_klein?icn=most_read

Locke EA (1991) The motivation sequence, the motivation hub, and the motivation core. Organizational Behavior and Human Decision Processes 50(2):288-299

Luc G, Altare C (2018) Social science research in a humanitarian emergency context. In: Schroeder D, Cook J, Hirsch F, Fenet S, Muthuswamy V (eds) Ethics dumping: case studies from NorthSouth research collaborations. Springer Briefs in Research and Innovation Governance, Berlin, p 9-14. https://link.springer.com/book/10.1007\%2F978-3-319-64731-9

Mansor M, Tayib D (2010). An empirical examination of organisational culture, job stress and job satisfaction within the indirect tax administration in Malaysia. International Journal of Business and Social Science 1(1):81-95

Marcum JA (2008). Medical axiology and values. In: An introductory philosophy of medicine: humanizing modern medicine. Philosophy and Medicine 99. Springer Science and Business Media, p 189-205

Martins N, Coetzee M (2011) Staff perceptions of organisational values in a large South African manufacturing company: exploring socio-demographic differences. SA Journal of Industrial Psychology 37(1):1-11

Mitchell LA (2015) Integrity and virtue: the forming of good character. The Linacre Quarterly 82(2):149-169

NMC (2018) The code: professional standards of practice and behaviour for nurses, midwives and nursing associates. Nursing \& Midwifery Council. https://www.nmc.org.uk/standards/code/

Ofori DF, Sokro E (2010). Examining the impact of organisational values on corporate performance in selected Ghanaian companies. Global Management Journal 2(1)

Ogletree TW (2004) Value and valuation. In: Post SG (ed) Encyclopedia of bioethics, 3rd edn. MacMillan Reference USA, New York, p 2539-2545

Owen R, Stilgoe J, Macnaghten P, Gorman M, Fisher E, Guston D (2013) A framework for responsible innovation. In: Owen, R, Bessant J, Heintz M (eds) Responsible innovation: managing the responsible emergence of science and innovation in society. John Wiley, London, p 27-50 
Pasewark WR, Riley ME (2010) It's a matter of principle: the role of personal values in investment decisions. Journal of Business Ethics 93(2):237-253

Philippa Foot P (1978) Virtues and vices. In: Virtues and vices and other essays in moral philosophy. Blackwell, Oxford, p 1-18

Pinto DC, Nique WM, Añaña EDS, Herter MM (2011) Green consumer values: how do personal values influence environmentally responsible water consumption? International Journal of Consumer Studies 35(2):122-131

Pogge T (2006) Justice. In: Borchert DM (ed) Encyclopedia of philosophy, 2nd edn (vol 4). Macmillan Reference, Detroit MI, p 862-870

Posner BZ (2010) Another look at the impact of personal and organizational values congruency. Journal of Business Ethics 97(4):535-541

Rawls J (1999) A theory of justice, revised edn. Oxford University Press, Oxford

Raz J (2001) Engaging reason: On the theory of value and action. Oxford University Press, Oxford

Resnik DB (2012) Ethical virtues in scientific research. Accountability in Research 19(6):329-343

Russell D C (2015) Aristotle on cultivating virtue. In: Snow, N (ed) Cultivating virtue: perspectives from philosophy, theology, and psychology. Oxford University Press, Oxford, p 37-38

Schwartz SH (2012) An overview of the Schwartz theory of basic values. Online Readings in Psychology and Culture 2(1):11

Sousa CM, Coelho F (2011) From personal values to creativity: evidence from frontline service employees. European Journal of Marketing 45(7/8):1029-1050

Threads Culture (nd) Core values examples. https://www.threadsculture.com/ core-values-examples/

UCLan (nd) The UCLan values. University of Central Lancashire. https://www.uclan.ac.uk/work/ life-at-uclan.php

UN (1948) Universal Declaration of Human Rights. http://www.un.org/en/ universal-declaration-human-rights/

UN (1992) Convention on Biological Diversity. https://www.cbd.int/doc/legal/cbd-en.pdf

Wang X, Li F, Sun Q (2018) Confucian ethics, moral foundations, and shareholder value perspectives: an exploratory study. Business Ethics: A European Review 27(3):260-271

WMA (2013) Declaration of Helsinki. World Medical Association. https://www.wma.net/policiespost/wma-declaration-of-helsinki-ethical-principles-for-medical-research-involving-humansubjects/

Wolfe PS (1997) The influence of personal values on issues of sexuality and disability. Sexuality and disability 15(2):69-90

Open Access This chapter is licensed under the terms of the Creative Commons Attribution 4.0 International License (http://creativecommons.org/licenses/by/4.0/), which permits use, sharing, adaptation, distribution and reproduction in any medium or format, as long as you give appropriate credit to the original author(s) and the source, provide a link to the Creative Commons licence and indicate if changes were made.

The images or other third party material in this chapter are included in the chapter's Creative Commons licence, unless indicated otherwise in a credit line to the material. If material is not included in the chapter's Creative Commons licence and your intended use is not permitted by statutory regulation or exceeds the permitted use, you will need to obtain permission directly from the copyright holder.

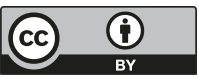

